\title{
Level of functioning, perceived work ability, and work status among psychiatric patients with major mental disorders
}

\section{Karpov, B.}

\author{
2017-07
}

Karpov , B , Joffe , G , Aaltonen , K, Suvisaari , J , Baryshnikov , I , Naatanen , P , Koivisto , M , Melartin , T , Oksanen , J , Suominen, K, Heikkinen, M \& Isometsa , E 2017 , ' Level of functioning, perceived work ability, and work status among psychiatric patients with major mental disorders ' , European Psychiatry , vol. 44 , pp. 83-89 . https://doi.org/10.1016/j.eurpsy.2017.03.010

http://hdl.handle.net/10138/297915

https://doi.org/10.1016/j.eurpsy.2017.03.010

publishedVersion

Downloaded from Helda, University of Helsinki institutional repository.

This is an electronic reprint of the original article.

This reprint may differ from the original in pagination and typographic detail.

Please cite the original version. 
Original article

\title{
Level of functioning, perceived work ability, and work status among psychiatric patients with major mental disorders
}

\author{
B. Karpov ${ }^{\text {a }}$, G. Joffe ${ }^{\text {a }}$, K. Aaltonen ${ }^{\text {a }}$, J. Suvisaari ${ }^{\text {b }}$, I. Baryshnikov ${ }^{\text {a }}$, P. Näätänen ${ }^{\text {a }}$, \\ M. Koivisto ${ }^{a}$, T. Melartin ${ }^{\mathrm{a}, 1}$, J. Oksanen ${ }^{\mathrm{b}}$, K. Suominen ${ }^{\mathrm{c}}$, M. Heikkinen ${ }^{\mathrm{a}}$, E. Isometsä ${ }^{\mathrm{a}, \mathrm{b}, *}$ \\ ${ }^{a}$ Department of Psychiatry, University of Helsinki and Helsinki University Hospital, P.O. Box 22 (Välskärinkatu 12 A), 00014 Helsinki, Finland \\ ${ }^{\mathrm{b}}$ National Institute for Health and Welfare, Department of Mental Health and Substance Abuse Services, Mannerheimintie 166, 00271 Helsinki, Finland \\ ${ }^{\mathrm{c}}$ Department of Social Services and Health Care, Nordenskiöldinkatu 20, 15-7, 00250 Helsinki, Finland
}

\section{A R T I C L E I N F O}

\section{Article history:}

Received 27 January 2017

Received in revised form 24 March 2017

Accepted 26 March 2017

Available online 7 April 2017

\section{Keywords:}

Functional impairment

Disability

Work status

Psychiatric care

\begin{abstract}
A B S T R A C T
Background: Major mental disorders are highly disabling conditions that result in substantial socioeconomic burden. Subjective and objective measures of functioning or ability to work, their concordance, or risk factors for them may differ between disorders.

Methods: Self-reported level of functioning, perceived work ability, and current work status were evaluated among psychiatric care patients with schizophrenia or schizoaffective disorder (SSA, $n=113$ ), bipolar disorder (BD, $n=99$ ), or depressive disorder (DD, $n=188$ ) within the Helsinki University Psychiatric Consortium Study. Correlates of functional impairment, subjective work disability, and occupational status were investigated using regression analysis.

Results: DD patients reported the highest and SSA patients the lowest perceived functional impairment. Depressive symptoms in all diagnostic groups and anxiety in SSA and BD groups were significantly associated with disability. Only $5.3 \%$ of SSA patients versus $29.3 \%$ or $33.0 \%$ of BD or DD patients, respectively, were currently working. About half of all patients reported subjective work disability. Objective work status and perceived disability correlated strongly among BD and DD patients, but not among SSA patients. Work status was associated with number of hospitalizations, and perceived work disability with current depressive symptoms.

Conclusions: Psychiatric care patients commonly end up outside the labour force. However, while among patients with mood disorders objective and subjective indicators of ability to work are largely concordant, among those with schizophrenia or schizoaffective disorder they are commonly contradictory. Among all groups, perceived functional impairment and work disability are coloured by current depressive symptoms, but objective work status reflects illness course, particularly preceding psychiatric hospitalizations.
\end{abstract}

(c) 2017 Elsevier Masson SAS. All rights reserved.

\section{Introduction}

According to Global Burden of Disease Study, mental disorders (MDs) are highly disabling conditions [1,2]. Moreover, same study demonstrates that poor functioning (measured in years lived with disability and disability-adjusted life years), leading to weak labour engagement of people with MDs [3,4], has resulted in an increased socioeconomic burden of MDs [5]. In addition to generally reduced employment [4], subjects with MDs have more

\footnotetext{
* Corresponding author at: Department of Psychiatry, P.O. Box 22 (Välskärinkatu 12 A), 00014 Helsinki, Finland. Fax: +358 947163735.

E-mail address: erkki.isometsa@hus.fi (E. Isometsä).

${ }^{1}$ Fax: +358947163735.
}

difficulties in returning to work after sick leave [6-8] and tend to retire earlier $[9,10]$ than the general population.

More specifically, major depressive disorder, bipolar disorder, and schizophrenia, along with anxiety disorders, are among the greatest contributors to the global burden of MDs [3]. Furthermore, depression is among the ten most disabling diseases worldwide $[1,11]$. However, most persons with depression and bipolar disorder manage to maintain employment status [12,13]. The accumulating vocational impairment is more severe in bipolar disorder than in depression, and the difference tends to grow over time [14]. In contrast to mood disorders, only about $20 \%$ of subjects with schizophrenia remain employed [15-17]. Interestingly, current labour status is often discordant with perceived work disability. Many authors have demonstrated that subjects with 
depression and, to some extent, bipolar disorder tend to overestimate their impairment in work ability [18-20], while subjects with schizophrenia spectrum disorders may underestimate it $[21,22]$.

In addition to prevalence, the risk factors for MD-related disability have been extensively studied. Many general population and clinical sample studies demonstrate roughly similar associations of functional impairment and work disability in depression, bipolar disorder, and schizophrenia with numerous socio-demographic and clinical factors. These include, for instance, older age [23-25], duration and number of hospitalizations [26,15], educational level $[23,25]$, and severity of current affective symptoms $[22,24,27,28]$. However, few clinical studies [29] have investigated functional impairment and its predictors concurrently in depression, bipolar disorder, and schizophrenia spectrum disorder within the same sampling frame and with similar methods. Therefore, similarities and differences between risk factors remain partly unclear. Moreover, we are not aware of studies investigating correlations between subjective and objective work disability across different mental disorders. Most studies on predictors of functional impairment in major mental disorders have investigated the impact of disorder-related symptoms (neurocognitive, affective, psychotic) [17,29-31]. Other clinical or psychological traits, e.g. comorbid borderline personality features and level of self-efficacy, may also considerably influence functioning [32-34].

We aimed, first, to investigate perceived level of functioning and ability to work and objective work status within a cohort of psychiatric care patients with either schizophrenia or schizoaffective disorder, bipolar disorder, or depressive disorder. We expected notable functional impairment in all patients, with the most severe disability in the schizophrenia or schizoaffective disorder group. Second, we investigated associations of functioning and work ability with putative risk factors regarding preceding course (age at onset, number of hospitalizations) and current state of illness (affective symptoms) as well as clinical and psychopathological variables (self-efficacy, borderline personality traits). We hypothesized that correlates of functioning and work disability would be broadly similar across groups, but concordance between subjective and objective measures would be lower among patients with schizophrenia spectrum disorders.

\section{Methods}

\subsection{Setting}

The methodology of the Helsinki University Psychiatric Consortium (HUPC) study has been presented in detail in the authors' previous reports [35-37] and is only briefly outlined below.

The HUPC study was carried out in secondary mental health services, including 10 community mental health centres, in 24 psychiatric inpatient units, in one day-care hospital, and in two residential communities of the Helsinki metropolitan area in 2011-2012. The study was approved by the Ethics Committee of Helsinki University Central Hospital.

\subsection{Sampling}

Inclusion criteria were age of 18 to 64 years and provision of written informed consent.

Patients were randomly drawn from all eligible patients, stratified by setting. Patients with mental retardation, neurodegenerative disorders, or insufficient Finnish language skills were excluded. We recruited only patients, whose condition was stable enough to allow responding to the questionnaires. Of 1361 eligible patients, 610 declined to participate and 304 were lost for other reasons. The final number of participants was 447 , resulting in a response rate of $33 \%$. In addition, 47 patients with a principal diagnosis of anxiety disorder, eating disorder, neuropsychiatric disorder, or substance use disorder were excluded from the current study, leaving 400 participants.

\subsection{Diagnostic assessment}

The principal clinical diagnoses given by attending psychiatrists were re-examined by the authors (K.A., I.B., M.K., and B.K.) following the criteria of the International Classification of Disease, 10th revision, Diagnostic Criteria for Research [38]. For the current study, patients were divided into three subgroups: schizophrenia or schizoaffective disorder (SSA, $n=113$ ), bipolar disorder (BD, $n=99$ ), and depressive disorders (DD, $n=188$ ).

\subsection{Measure of functional impairment}

The Sheehan Disability Scale (SDS) $[39,40]$ is a three-item selfreport scale to assess functional impairment on three domains: work, social life or leisure activities, and home life or family responsibilities. Each item is scored from zero to 10 . The three items can be summed into a single dimensional scale of global functional impairment ranging from zero (no impairment) to 30 (high impairment). The SDS has no recommended cut-off score. However, a score of five and more on any of the scales is considered to indicate significant functional impairment.

\subsection{Other measures}

The Beck Depression Inventory (BDI) [41] is a self-report questionnaire for measuring the severity of depression symptoms. The Overall Anxiety Severity and Impairment Scale (OASIS) [42] is a self-report questionnaire to assess severity and impairment associated with anxiety. The General Self-Efficacy Scale (GSE) [43] is a selfreport instrument to assess perceived self-efficacy regarding stressful life events. The McLean Screening Instrument for borderline personality disorder (MSI-BPD, hereafter MSI) [44] is a self-report questionnaire for screening for borderline personality disorder. All the scales had at least good internal consistency (Cronbach's alpha for total SDS 0.80; OASIS 0.84; BDI 0.91; GSE 0.93; MSI 0.92).

\subsection{Assessment of work status and ability to work}

In Finland, disability pension could be granted after 300 days of sick leave in a two-year period if the person was still considered unable to work or find employment that fits person's vocational qualifications because of an illness. That also applies to people working in a household. The Social Insurance Institution of Finland or other pension providers grant a pension based on the person's current and expected functional level presented in medical certificates of the attending physician. The authors collected information from medical records and certificates (for sick leave or disability pension) on a patient's current work/ employment status, creating a three-item nominal variable (working, sick leave, or disability pension/rehabilitation subsidy). For further analyses, this variable was modified to a dichotomous as working and not-working (sick leave and disability pension/ rehabilitation subsidy).

Patients were asked about their perceived ability to work, producing ordinal variable: 1 - able to work, 2 - reduced work ability, 3 - unable to work. For further analyses, this variable was transformed into the dichotomous form of able to work (items 1 and 2 combined)/unable to work. This categorization has been used also in previous studies $[23,24]$. Data on ability to work (work 
status) gathered from medical records were designated as "objective" and from patients as "subjective".

\subsection{Statistical analyses}

Relationships between nominal variables were tested with $\mathrm{Chi}^{2}$ test and between nominal/ordinal and continuous variables with Mann-Whitney U-test or Kruskal-Wallis test. The variables represented domains of demographics (age, gender), societal status (marital status, number of children, education), course of disease (age at onset, number of hospitalizations), and current symptoms (depressive, anxiety, borderline personality symptoms, self-efficacy). In case of skewed distributions, we used nonparametric tests. The relationships between total SDS and other continuous variables (age, age at onset, number of hospitalizations, measurement scales) were tested with Spearman's bivariate correlation analysis (BCA). Variables associated with SDS and work ability most consistently across all diagnostic groups in univariate analyses were included in regression analyses. Thus, linear regression models were built to estimate the associations between total SDS and measures that correlated with it in BCA. These measures were BDI, OASIS, and GSE. Also, the not correlated but clinically relevant variables of age, age at onset, number of hospitalizations, and duration of treatment were included in the regression analyses. The same logic was applied in logistic regression models to investigate associations between objective and subjective ability to work. Thus, the regression model included age, age at onset, number of hospitalizations, BDI, OASIS, GSE, and SDS. To avoid cross-loading of two different self-report work ability measures, we excluded the work domain from the total SDS variable. Thus, SDS was included in the analysis as a measure of other functioning, not work-related. Relationships of objective (ordinal variable of work status) and subjective work ability (initial ordinal variable) within diagnostic groups were explored with Spearman's bivariate correlation analysis. Statistical analysis was performed using the Statistical Package for the Social Sciences [45].

\section{Results}

\subsection{Socio-demographic and background data}

Patients in all diagnostic groups were middle-aged and, with the exception of the SSA group, mainly women (Table 1). The SSA group had the highest number of unmarried and childless patients across all groups $(P<0.001)$. Most patients had a professional education. Subjects with BD had comorbid alcohol use disorders (AUDs) more often than other patients $(P=0.012)$. The mean age at onset of the principal disorder was seemingly the same across diagnostic groups, being, however, significantly lowest in SSA patients $(P=0.006)$. These patients also had a longer history of treatment and a higher number of hospitalizations than their mood disorder counterparts $(P<0.001)$. DD patients had significantly higher scores on BDI and OASIS and lower scores on GSE scales than BD or SSA patients.

\subsection{Self-reported functioning on the Sheehan Disability Scale}

Of all diagnostic groups, subjects with DD collected the highest and subjects with SSA the lowest scores on SDS in all three domains (Table 2). The mean scores on each of the three scales exceeded five in all groups (except for "family life" scale in SSA patients), indicating notable perceived functioning impairment. No sociodemographic factor was associated with the SDS distribution in any diagnostic group. However, in all patients, both SDS total scores and subscale scores directly correlated with a broad spectrum of clinical and psychopathological variables such as BDI, OASIS, MSI, and GSE (negative correlation) (data not shown). Associations with total SDS, revealed in linear regression analysis, were nonetheless fewer and showed less congruity (Table 3). Thus, BDI was the only one measure associated with SDS across all diagnostic groups. The OASIS had regression weight in SSA and BD groups, and GSE in SSA and DD groups. Older age was associated with functional impairment only in DD patients.

\subsection{Objective work status}

Overall, a high proportion of all patients had sick leave or disability pension (Table 4). Of all subjects with SSA, only 5.3\% remained at work, while such figures for BD and DD groups were $29.3 \%$ and $33.0 \%$, respectively. Gender, marital status, and educational level did not affect ability to work in any diagnostic group (data not shown). Older age was associated with work disability in the BD group $(P=0.003)$, and earlier age at onset in the SSA group $(P=0.010)$. Subjects of the SSA and BD groups with repeated hospitalizations $(P=0.013$ and $P=0.030$, respectively) and longer duration of treatment $(P=0.003$ and $P=0.014$,

Table 1

Socio-demographic and clinical characteristics of the sample.

\begin{tabular}{|c|c|c|c|c|c|c|c|c|c|}
\hline & \multicolumn{2}{|l|}{ SSA } & \multicolumn{2}{|l|}{$\mathrm{BD}$} & \multicolumn{2}{|l|}{$\mathrm{DD}$} & \multicolumn{2}{|c|}{ Total } & \multirow[t]{2}{*}{$P$-value } \\
\hline & $n$ & $\%$ & $n$ & $\%$ & $n$ & $\%$ & $n$ & $\%$ & \\
\hline Number & 113 & 28.3 & 99 & 24.8 & 188 & 46.9 & 400 & 100.0 & \\
\hline Female & 54 & 47.8 & 63 & 63.6 & 146 & 77.7 & 263 & 65.8 & $<0.001^{\mathrm{a}}$ \\
\hline Marital status & & & & & & & & & $<0.001^{\mathrm{a}}$ \\
\hline Married/cohabitating & 10 & 9.1 & 37 & 37.4 & 68 & 36.6 & 115 & 29.1 & \\
\hline Divorced/widowed & 19 & 17.3 & 30 & 30.3 & 39 & 21.0 & 88 & 22.3 & \\
\hline Unmarried & 81 & 73.6 & 32 & 32.3 & 79 & 42.4 & 192 & 48.6 & \\
\hline No children & 97 & 89.0 & 58 & 59.8 & 130 & 70.7 & 285 & 73.1 & $<0.001^{\mathrm{a}}$ \\
\hline Professional education & 68 & 61.8 & 71 & 71.7 & 121 & 65.1 & 260 & 65.8 & $0.307^{\mathrm{a}}$ \\
\hline AUD diagnosis & 25 & 22.1 & 30 & 30.3 & 29 & 15.4 & 84 & 21.0 & $0.012^{\mathrm{a}}$ \\
\hline Inpatients & 36 & 31.9 & 20 & 20.2 & 34 & 18.1 & 102 & 22.8 & $0.018^{\mathrm{a}}$ \\
\hline Age, mean (SD) & \multicolumn{2}{|c|}{$44.3(12.4)$} & \multicolumn{2}{|c|}{$43.4(12.3)$} & \multicolumn{2}{|c|}{$41.2(13.3)$} & \multicolumn{2}{|c|}{$42.0(13.0)$} & $0.002^{\mathrm{b}}$ \\
\hline Age at onset, mean (SD) & \multicolumn{2}{|c|}{$30.5(12.3)$} & \multicolumn{2}{|c|}{$35.0(12.7)$} & \multicolumn{2}{|c|}{$35.5(14.0)$} & \multicolumn{2}{|c|}{$34.0(13.4)$} & $0.006^{\mathrm{b}}$ \\
\hline Number of hospitalizations, mean (SD) & \multicolumn{2}{|c|}{$2.0(1.1)$} & \multicolumn{2}{|c|}{$1.5(1.3)$} & \multicolumn{2}{|c|}{$0.9(1.2)$} & \multicolumn{2}{|c|}{$1.4(1.3)$} & $<0.001^{\mathrm{b}}$ \\
\hline $\mathrm{BDI}$, mean $(\mathrm{SD})$ & \multicolumn{2}{|c|}{$18.0(12.2)$} & \multicolumn{2}{|c|}{$22.3(11.5)$} & \multicolumn{2}{|c|}{$27.7(12.5)$} & \multicolumn{2}{|c|}{$23.6(12.8)$} & $<0.001^{\mathrm{b}}$ \\
\hline OASIS, mean (SD) & \multicolumn{2}{|c|}{$9.4(5.5)$} & \multicolumn{2}{|c|}{$10.8(4.4)$} & \multicolumn{2}{|c|}{$11.0(4.8)$} & \multicolumn{2}{|c|}{$10.5(5.0)$} & $0.040^{\mathrm{b}}$ \\
\hline GSE, mean (SD) & \multicolumn{2}{|c|}{$21.7(7.8)$} & \multicolumn{2}{|c|}{$21.2(6.3)$} & \multicolumn{2}{|c|}{$19.1(6.3)$} & \multicolumn{2}{|c|}{$20.4(6.8)$} & $0.006^{\mathrm{b}}$ \\
\hline MSI, mean (SD) & \multicolumn{2}{|c|}{$5.2(3.0)$} & \multicolumn{2}{|c|}{$6.0(2.5)$} & \multicolumn{2}{|c|}{$5.4(2.7)$} & \multicolumn{2}{|c|}{$5.5(2.8)$} & $0.131^{\mathrm{b}}$ \\
\hline
\end{tabular}

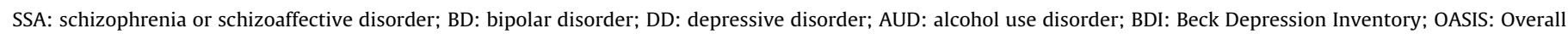
Anxiety Severity and Impairment Scale; GSE: General Self-Efficacy Scale; MSI: McLean Screening Instrument for borderline personality disorder.

a $\mathrm{Chi}^{2}$ test.

b Kruskall-Wallis test (between-group comparison). 
Table 2

Distribution of Sheehan Disability Scale scores by domains across diagnostic groups.

\begin{tabular}{|c|c|c|c|c|}
\hline Mean (SD) & $\operatorname{SSA}(n=113)$ & $\mathrm{BD}(n=99)$ & $\mathrm{DD}(n=188)$ & $P$-value \\
\hline SDS summary & $16.3(7.7)$ & $17.7(7.9)$ & $20.9(7.6)$ & $<0.001^{\mathrm{a}}$ \\
\hline Work & $6.3(3.2)$ & $6.7(3.3)$ & $7.3(3.0)$ & $<0.001^{\mathrm{a}}$ \\
\hline Social life or leisure activities & $5.5(3.1)$ & $5.7(3.0)$ & $6.9(2.9)$ & $<0.001^{\mathrm{a}}$ \\
\hline Family life or home responsibilities & $4.4(3.3)$ & $5.3(2.9)$ & $6.4(2.9)$ & $0.019^{\mathrm{a}}$ \\
\hline
\end{tabular}

SSA: schizophrenia or schizoaffective disorder; BD: bipolar disorder; DD: depressive disorder; SDS: Sheehan Disability Scale.

a Kruskall-Wallis test.

Table 3

Linear regression analysis of clinical correlates for Sheehan Disability Scale within diagnostic groups.

\begin{tabular}{|c|c|c|c|c|c|c|c|c|c|}
\hline & \multicolumn{3}{|c|}{$\operatorname{SSA}(n=113)$} & \multicolumn{3}{|c|}{$\mathrm{BD}(n=99)$} & \multicolumn{3}{|c|}{$\mathrm{DD}(n=188)$} \\
\hline & B & $\beta$ & Sig. & B & $\beta$ & Sig. & B & $\beta$ & Sig. \\
\hline Age & 0.02 & 0.02 & 0.654 & 0.01 & 0.02 & 0.876 & 0.25 & 0.44 & 0.004 \\
\hline Age at onset & -0.04 & -0.05 & 0.407 & -0.03 & -0.05 & 0.716 & -0.15 & -0.30 & 0.071 \\
\hline Number of hospitalizations & 0.74 & 0.10 & 0.136 & 0.19 & 0.03 & 0.408 & 0.49 & 0.06 & 0.256 \\
\hline BDI & 0.15 & 0.27 & 0.026 & 0.35 & 0.50 & 0.000 & 0.30 & 0.50 & 0.000 \\
\hline OASIS & 0.40 & 0.34 & 0.007 & 0.44 & 0.24 & 0.032 & 0.15 & 0.12 & 0.196 \\
\hline GSE & -0.24 & -0.26 & 0.006 & -0.06 & 0.05 & 0.594 & -0.20 & -0.18 & 0.010 \\
\hline MSI & $\begin{array}{l}0.38 \\
R^{2}=0.432\end{array}$ & 0.15 & 0.125 & $\begin{array}{l}0.25 \\
R^{2}=0.402\end{array}$ & 0.01 & 0.933 & $\begin{array}{l}0.16 \\
R^{2}=0.465\end{array}$ & 0.06 & 0.399 \\
\hline
\end{tabular}

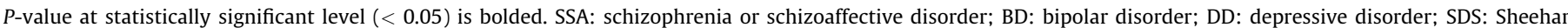

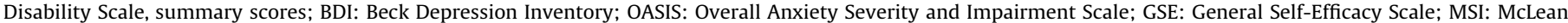
Screening Instrument for borderline personality disorder; $\mathrm{R}^{2}$ : adjusted R square.

Table 4

Objective work status and subjective ability to work.

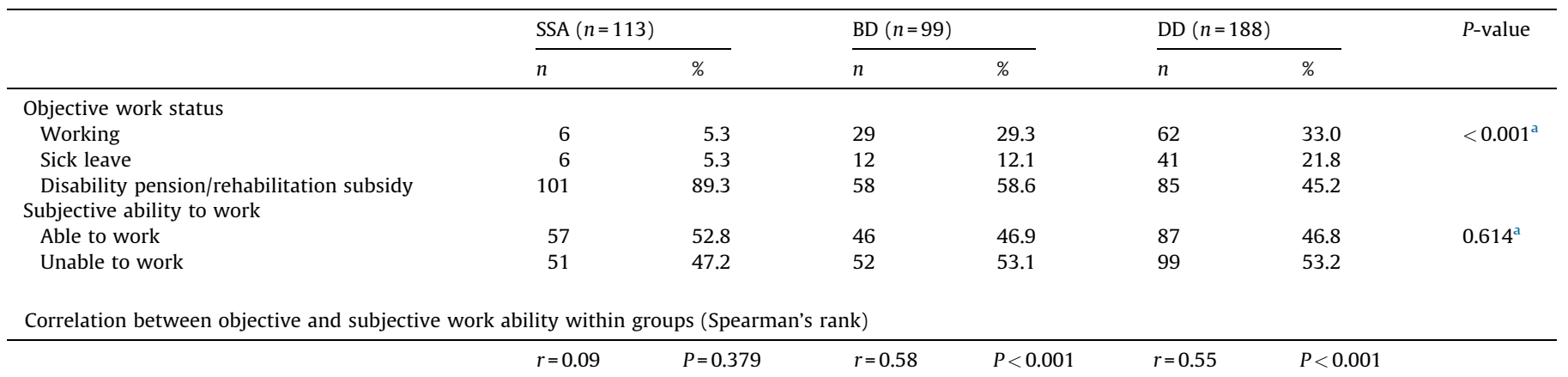

SSA: schizophrenia or schizoaffective disorder; BD: bipolar disorder; DD: depressive disorder.

${ }^{a} \mathrm{Chi}^{2}$ test (between diagnostic groups comparison).

respectively) were more often withdrawn from work than DD patients. BD patients with work disability showed higher SDS scores, and DD patients with work disability higher SDS, OASIS, and BDI scores and lower GSE scores than their able counterparts. No such associations emerged in the SSA group (data not shown), nor were any associations found for MSI in any group. Logistic regression analysis demonstrated direct associations of work disability with SDS and number of hospitalizations in all groups and an inverse association with GSE in the SSA group (Table 5). In addition, age and age at onset had regression weight in the BD group. The results remained the same when SDS was excluded from the model.

\subsection{Subjective ability to work}

Near half of the patients of all groups reported work disability (Table 4). Perceived work disability was related to older age in SSA and DD groups $(P=0.001$ and $P=0.004$, respectively) and to number of hospitalizations in the BD group $(P=0.036)$. No associations emerged regarding other socio-demographic and background characteristics (data not shown). Patients with perceived work disability of all groups scored higher in OASIS, $\mathrm{BDI}$, and SDS and lower in GSE, and only in the DD group had higher
MSI scores than their able to work counterparts (data not shown). Logistic regression analysis revealed less consistent associations (Table 5). Thus, SDS had regression weight in BD and DD groups, and BDI in all groups. The exclusion of SDS from this model did not change the results. The MSI dropped from the final regression model because of its insignificance in SSA and BD groups.

\subsection{Objective work status vs. subjective work ability}

The proportions of patients working and subjectively able to work correlated moderately strongly and significantly among BD and DD patients $(P<0.001)$, but not in the SSA group $(P=0.379)$.

\section{Discussion}

This study investigated level of functioning plus subjective and objective ability to work among psychiatric care patients. Most of the patients, irrespective of diagnosis, reported marked functional impairment. Of all diagnostic groups, subjects with schizophrenia or schizoaffective disorder were mostly outside the labour force, but concurrently subjectively experienced the least functional difficulties. In contrast, among patients with mood disorders, objective and subjective indicators for ability to work were broadly 
Table 5

Multivariate logistic regression analysis of clinical correlates for objective and subjective ability to work within diagnostic groups.

\begin{tabular}{|c|c|c|c|c|c|c|}
\hline & \multicolumn{2}{|c|}{$\operatorname{SSA}(n=113)$} & \multicolumn{2}{|c|}{$\mathrm{BD}(n=99)$} & \multicolumn{2}{|c|}{$\mathrm{DD}(n=188)$} \\
\hline & $\mathrm{B}$ & Sig. & B & Sig. & B & Sig. \\
\hline \multicolumn{7}{|l|}{ Objective work status $^{a}$} \\
\hline Age & 0.03 & 0.623 & 0.28 & 0.002 & 0.05 & 0.238 \\
\hline Age at onset & -0.30 & 0.155 & -0.21 & 0.009 & -0.06 & 0.120 \\
\hline Number of hospitalizations & 2.06 & 0.019 & 0.77 & 0.005 & 0.43 & 0.013 \\
\hline BDI & 0.01 & 0.906 & 0.04 & 0.461 & 0.03 & 0.172 \\
\hline OASIS & 0.25 & 0.451 & 0.04 & 0.700 & 0.06 & 0.288 \\
\hline GSE & -0.36 & 0.026 & -0.08 & 0.198 & 0.02 & 0.578 \\
\hline SDS (except “work" item) & 0.43 & 0.031 & 0.17 & 0.005 & 0.14 & 0.000 \\
\hline \multicolumn{7}{|l|}{ Subjective ability to work ${ }^{\mathrm{b}}$} \\
\hline Age & 0.05 & 0.037 & 0.02 & 0.560 & 0.03 & 0.399 \\
\hline Age at onset & -0.01 & 0.698 & 0.02 & 0.622 & 0.05 & 0.130 \\
\hline Number of hospitalizations & 0.14 & 0.516 & 0.82 & 0.009 & 0.16 & 0.329 \\
\hline BDI & 0.09 & 0.005 & 0.13 & 0.023 & 0.10 & 0.000 \\
\hline OASIS & 0.03 & 0.657 & 0.11 & 0.300 & 0.08 & 0.144 \\
\hline GSE & -0.01 & 0.838 & -0.07 & 0.232 & -0.06 & 0.165 \\
\hline SDS (except “work” item) & 0.07 & 0.121 & 0.23 & 0.002 & 0.22 & 0.000 \\
\hline
\end{tabular}

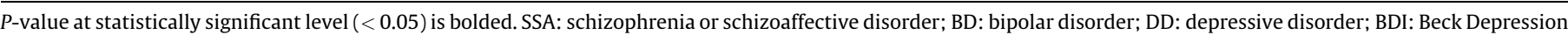
Inventory; OASIS: Overall Anxiety Severity and Impairment Scale; GSE: General Self-Efficacy Scale; SDS: Sheehan Disability Scale ("work" item excluded).

${ }^{a}$ Information on work status collected from medical records/certificates by authors.

b Patients' perceived ability to work.

convergent. Within all groups, current depressive symptoms contributed to self-reported impairment, while recurrent psychiatric hospitalizations were associated with objective work status.

\subsection{Self-reported functional impairment}

Perceived level of functioning, as measured by the Sheehan Disability Scale, was clearly deteriorated in all diagnostic groups. However, somewhat unexpectedly, the most subjectively impaired group across all three domains was the unipolar depressive patients. Unlike our study, most previous studies conducted in psychiatric settings have compared disability only between two major mental disorders. Wide variations in observed functioning have been reported. For instance, van der Voort et al. [46] found more prominent functional impairment in BD patients than in DD patients. Bowie et al. [30] and Simonsen et al. [47] reported more severe disability in schizophrenia than in BD. In contrast, Lee et al. [31], in comparing patients with DD, BD, or psychosis, did not find the principal diagnosis of mental disorder to be a significant predictor of functional outcome, which was instead predicted by neuropsychological functioning. However, the same group in further work found more favourable vocational prognosis for patients with BD rather than DD or schizophrenia spectrum disorder [29].

Correlates of perceived disability could conceivably differ markedly between the major mental disorders. However, we found that depressive symptoms consistently appeared as the major contributor to perceived impairment not only in DD and BD but also in SSA. Depressive symptoms are essential for poor psychosocial functioning in mood disorders [26,46,48-50] overall, but the negative bias in self-referential thinking in depression [51] may be of particular importance for an exaggeratedly negative view of perceived level of functioning. Thus, finding DD patients to report the highest subjective functional impairment of all groups is, perhaps, not surprising, as they experienced the most severe depressive symptoms (BDI) as well. In schizophrenia spectrum disorders, affective symptoms impair functioning as a secondary condition; in part, some negative symptoms, such as anhedonia, may overlap with those of depression [52-55]. Overall, our finding of depressive and, to some extent, anxiety symptoms contributing to functional impairment highlights the importance of measuring them when assessing level of functioning.

\subsection{Work status}

Differences in work status between the diagnostic groups were notable. Only few (5.3\%) of our SSA patients were working, in contrast to nearly half of the mood disorder patients. Despite DD patients reporting the highest level of functional impairment on the SDS, they were still the most employed group of all. Such a discrepancy could refer to overall subjective underestimation of functional capacity by patients with depression compared with objective assessment $[18,19,22]$. Regression analyses indicated the association of numbers of hospitalizations with current labour status as unemployed, pensioned, or being on sick leave. Previous studies also demonstrate that preceding course of disease (i.e. duration of illness and hospitalizations required) is strongly related to subsequent job loss due to disability pension in schizophrenia spectrum disorders [53,56], bipolar disorder [24], and depression [23,27]. We assume that number of hospitalizations represents a proxy for the overall severity, duration, chronicity, and recurrent course of the principal mental disorder, which jointly will commonly lead to disability pension. Another major correlate of long-term work disability or pensioning across all diagnostic groups was the perceived functional impairment as measured by the SDS. The studies on this topic vary by methodology and functioning assessment tools. Nevertheless, poor self-rated functioning is likely to predict negative outcome of employment in all mental disorders [23,24,57-59]. However, regardless of the primary psychopathology, our findings highlight the importance of overall level of functioning for retaining occupational roles. Work status was correlated not only specifically with perceived disability at work but also with functioning in other areas of life. Thus, in all three diagnostic groups, both poor overall functioning and the factors jointly resulting in repeated hospitalizations were the strongest correlates for poor work status.

\subsection{Objective work status vs. subjective work ability}

In terms of perceived work disability, the most significant finding was a marked gap between actual labour status and subjective work ability in the SSA group. While again only $5.3 \%$ of these patients remained employed, concurrently half of them perceived themselves as able to work. Such findings are in accordance with the general phenomenon of discordance between self-reporting and assessor-rating in SSA patients. Previous studies 
have indicated that, due to low insight and neurocognitive and, to some extent, negative symptoms, patients with schizophrenia spectrum disorder tend to markedly overestimate their functional level [21,22] and overall quality of life [60,61] comparing to the evaluation of a clinician. Additionally, our result of high-perceived work ability in SSA patients could partially reflect the finding that subjects with severe mental illness (i.e. schizophrenia spectrum disorders) still strongly desire to work [25]. However, it is possible that besides poor insight particularly long-term SSA patients outside working life may have a different frame of reference for judging their functioning. Because of such a discordance, clinicians should evaluate functioning of SSA patients comprehensively, including both subjective and objective aspects [62]. Their work status is likely not only related to their illness, but also dependent on context (social support, health care system, rehabilitation, etc.). Furthermore, low employment in the SSA group raises the issue of need for more effective employment programs for such patients.

Contrary to the SSA group, perceived and actual work ability were moderately strongly correlated in our mood disorder patients. Their level of self-reported work ability was, nevertheless, slightly higher than their vocational status. Such a disproportion could result from delayed functional recovery compared with syndromal remission [46]. Thus, relief of symptoms is likely to enhance subjective but not objective ability to work.

The correlates of perceived work ability were roughly akin to those of self-reported functional impairment. The most consistent finding across all groups was the association of subjective work disability with current depressive symptoms. Thus, clinicians should pay attention to carefully uncovering and effectively treating affective symptoms regardless of their psychopathological domain to improve the patient's engagement in rehabilitation programmes and eventually expedite their return to work.

\subsection{Study strengths and limitations}

Strengths of this study include investigation of reported functioning, perceived ability to work, and work status along with clinical characteristics simultaneously across diagnostically heterogeneous (schizophrenia or schizoaffective disorder, bipolar disorder, and depression) psychiatric care patients in the Helsinki metropolitan area. This allowed comparison of the diagnostic groups in terms of the measures of functioning, their correlates, and the consistency of objective and subjective measures.

Our study also has several limitations. First, all results for the SSA group should be interpreted with caution due to the low number $(n=6)$ of subjects remaining at work, and thus, the low statistic power in some bivariate and multivariate analyses. Second, as this study, which included a long survey, was performed in a busy routine clinical practice, the response rate was only $33 \%$. However, according to register-based analysis of representativeness, our sample did not differ from the patient populations of participating organizations in terms of gender or age. Regarding demographic characteristics, our study is comparable with the earlier screening-based Vantaa Depression Study and Jorvi Bipolar Study $[63,64]$, but the proportion of patients with disability pension was $18-19 \%$ higher in this study $[23,24]$. Third, the generalizability of the findings of this Helsinki metropolitan area study (also considering relatively low response rate) to other settings needs to be verified. Fourth, principal clinical diagnoses were set in psychiatric care by psychiatrists and residents (although not always based on structured interviews), and in addition verified by the authors from available medical records. Additionally, we did not use any clinician-rated work ability measures and utilized only data on employment status as an objective measure of work ability. The information on employment status was collected only from medical records and was not corroborated from the Finnish Social Insurance Institution or other registers. Fifth, because this was a cross-sectional study, no firm conclusions can be made on causal relationships between demographic or clinical variables and level of functioning or work ability. Sixth, recall bias could affect self-report measures, and some patients could under- or overestimate their symptoms, both factors bias our analyses. Seventh, the study included multiple descriptive statistical analyses, which increases risk of spurious findings. However, we used multivariate regression models to test our hypotheses on risk factors of functional impairment and work disability. Eighth, cognitive functioning is a highly relevant factor influencing functional outcome, but could not be assessed in this study.

\section{Conclusions}

Psychiatric care patients commonly suffer from marked disability and eventually end up outside the labour force. However, while among patients with mood disorders objective and subjective indicators of ability to work are largely concordant, among those with schizophrenia or schizoaffective disorder they are commonly contradictory. Among all groups, perceived functional impairment and work disability are coloured by current depressive symptoms. In contrast, objective work status reflects illness course, particularly number of preceding psychiatric hospitalizations.

\section{Disclosure of interest}

The authors declare that they have no competing interest.

\section{References}

[1] Vos T, Allen C, Arora M, Barber RM, Bhutta ZA, Brown A, et al. GBD 2015 Disease and Injury Incidence and Prevalence Collaborators. Global, regional, and national incidence, prevalence, and years lived with disability for 310 diseases and injuries, 1990-2015: a systematic analysis for the Global Burden of Disease Study 2015. Lancet 2016;388(10053):1545-602.

[2] Vos T, Flaxman AD, Naghavi M, Lozano R, Michaud C, Ezzati M, et al. Years lived with disability (YLDs) for 1160 sequelae of 289 diseases and injuries 19902010: a systematic analysis for the Global Burden of Disease Study 2010. Lancet 2012:380(9859):2163-96.

[3] Whiteford HA, Ferrari AJ, Degenhardt L, Feigin V, Vos T. The global burden of mental, neurological and substance use disorders: an analysis from the Global Burden of Disease Study 2010. PLoS One 2015;10(2):e0116820.

[4] Mojtabai R, Stuart EA, Hwang I, Susukida R, Eaton WW, Sampson N, et al. Longterm effects of mental disorders on employment in the National Comorbidity Survey ten-year follow-up. Soc Psychiatry Psychiatr Epidemiol 2015;50(11): 1657-68.

[5] Murray CJ, Vos T, Lozano R, Naghavi M, Flaxman AD, Michaud C, et al. Disability-adjusted life years (DALYs) for 291 diseases and injuries in 21 regions, 1990-2010: a systematic analysis for the Global Burden of Disease Study 2010. Lancet 2012;380(9859):2197-223.

[6] Laaksonen M, Gould R. Return to work after temporary disability pension in Finland. J Occup Rehabil 2015;25(3):471-80.

[7] Ekberg K, Wahlin C, Persson J, Bernfort L, Oberg B. Early and late return to work after sick leave: predictors in a cohort of sick-listed individuals with common mental disorders. J Occup Rehabil 2015;25(3):627-37.

[8] Netterstrom B, Eller NH, Borritz M. Prognostic factors of returning to work after sick leave due to work-related common mental disorders: a one- and threeyear follow-up study. Biomed Res Int 2015;596572. http://dx.doi.org/10.1155/ 2015/596572 [Epub 2015 Oct 18].

[9] Lahelma E, Pietilainen O, Rahkonen O, Lallukka T. Common mental disorders and cause-specific disability retirement. Occup Environ Med 2015;72(3): $181-7$.

[10] Kaila-Kangas L, Haukka E, Miranda H, Kivekas T, Ahola K, Luukkonen R, et al. Common mental and musculoskeletal disorders as predictors of disability retirement among Finns. J Affect Disord 2014;165:38-44.

[11] Lopez AD, Mathers CD, Ezzati M, Jamison DT, Murray CJ. Global and regional burden of disease and risk factors, 2001: systematic analysis of population health data. Lancet 2006;367(9524):1747-57.

[12] Chen FP, Samet S, Gorroochurn P, O'Hara KM. Characterizing factors of employment status in persons with major depressive disorder. Eval Health Prof 2016;39(3):263-81.

[13] Marwaha S, Durrani A, Singh S. Employment outcomes in people with bipolar disorder: a systematic review. Acta Psychiatr Scand 2013;128(3):179-93. 
[14] Goldberg JF, Harrow M. A 15-year prospective follow-up of bipolar affective disorders: comparisons with unipolar nonpsychotic depression. Bipolar Disord $2011 ; 13(2): 155-63$.

[15] Miettunen J, Lauronen E, Veijola J, Koponen H, Saarento O, Taanila A, et al. Socio-demographic and clinical predictors of occupational status in schizophrenic psychoses - follow-up within the Northern Finland 1966 Birth Cohort. Psychiatry Res 2007;150(3):217-25.

[16] Marwaha S, Johnson S. Schizophrenia and employment - a review. Soc Psychiatry Psychiatr Epidemiol 2004;39(5):337-49.

[17] Rosenheck R, Leslie D, Keefe R, McEvoy J, Swartz M, Perkins D, et al. Barriers to employment for people with schizophrenia. Am J Psychiatry 2006;163(3): 411-7.

[18] Pranjic N, Males-Bilic L. Work ability index, absenteeism and depression among patients with burnout syndrome. Mater Sociomed 2014;26(4):249-52.

[19] Zimmerman M, Martinez JA, Attiullah N, Friedman M, Toba C, Boerescu DA, et al. Why do some depressed outpatients who are in remission according to the Hamilton Depression Rating Scale not consider themselves to be in remission? J Clin Psychiatry 2012;73(6):790-5 [Physicians Postgraduate Press, Inc.].

[20] Fagiolini A, Kupfer DJ, Masalehdan A, Scott JA, Houck PR, Frank E. Functional impairment in the remission phase of bipolar disorder. Bipolar Disord 2005;7(3):281-5.

[21] Oorschot M, Lataster T, Thewissen V, Lardinois M, van Os J, Delespaul PA, et al. Symptomatic remission in psychosis and real-life functioning. Br J Psychiatry 2012;201(3):215-20.

[22] Huppert JD, Weiss KA, Lim R, Pratt S, Smith TE. Quality of life in schizophrenia: contributions of anxiety and depression. Schizophr Res 2001;51(2-3):171-80.

[23] Holma IA, Holma KM, Melartin TK, Rytsala HJ, Isometsa ET. A 5-year prospective study of predictors for disability pension among patients with major depressive disorder. Acta Psychiatr Scand 2012;125(4):325-34.

[24] Arvilommi P, Suominen K, Mantere O, Valtonen H, Leppamaki S, Isometsa E. Predictors of long-term work disability among patients with type I and II bipolar disorder: a prospective 18-month follow-up study. Bipolar Disord 2015;17(8):821-35

[25] Tsang HW, Leung AY, Chung RC, Bell M, Cheung WM. Review on vocational predictors: a systematic review of predictors of vocational outcomes among individuals with schizophrenia: an update since 1998. Aust N Z J Psychiatry 2010;44(6):495-504.

[26] Gutierrez-Rojas L, Jurado D, Gurpegui M. Factors associated with work, social life and family life disability in bipolar disorder patients. Psychiatry Res 2011;186(2-3):254-60.

[27] Rytsälä HJ, Melartin TK, Leskela US, Sokero TP, Lestela-Mielonen PS, Isometsa ET. Predictors of long-term work disability in Major Depressive Disorder: a prospective study. Acta Psychiatr Scand 2007;115(3):206-13.

[28] Braga RJ, Mendlowicz MV, Marrocos RP, Figueira IL. Anxiety disorders in outpatients with schizophrenia: prevalence and impact on the subjective quality of life. J Psychiatr Res 2005;39(4):409-14

[29] Lee RS, Hermens DF, Naismith SL, Lagopoulos J, Jones A, Scott J, et al. Neuropsychological and functional outcomes in recent-onset major depression, bipolar disorder and schizophrenia spectrum disorders: a longitudinal cohort study. Transl Psychiatry 2015;5:e555.

[30] Bowie CR, Depp C, McGrath JA, Wolyniec P, Mausbach BT, Thornquist MH, et al. Prediction of real-world functional disability in chronic mental disorders: a comparison of schizophrenia and bipolar disorder. Am J Psychiatry 2010;167(9):1116-24.

[31] Lee RS, Hermens DF, Redoblado-Hodge MA, Naismith SL, Porter MA, Kaur M, et al. Neuropsychological and socio-occupational functioning in young psychiatric outpatients: a longitudinal investigation. PLoS One 2013;8(3):e58176.

[32] Bahorik AL, Eack SM. Examining the course and outcome of individuals diagnosed with schizophrenia and comorbid borderline personality disorder. Schizophr Res 2010;124(1-3):29-35.

[33] Zimmerman M, Martinez JH, Young D, Chelminski I, Dalrymple K. Sustained unemployment in psychiatric outpatients with bipolar depression compared to major depressive disorder with comorbid borderline personality disorder. Bipolar Disord 2012;14(8):856-62.

[34] Cardenas V, Abel S, Bowie CR, Tiznado D, Depp CA, Patterson TL, et al. When functional capacity and real-world functioning converge: the role of selfefficacy. Schizophr Bull 2013;39(4):908-16.

[35] Norman SB, Cissell SH, Means-Christensen AJ, Stein MB. Development and validation of an Overall Anxiety Severity and Impairment Scale (OASIS). Depress Anxiety 2006;23(4):245-9.

[36] Baryshnikov I, Aaltonen K, Koivisto M, Näätänen P, Karpov B, Melartin T, et al Differences and overlap in self-reported symptoms of bipolar disorder and borderline personality disorder. Eur Psychiatry 2015;30(8):914-9.

[37] Aaltonen K, Näätänen P, Heikkinen M, Koivisto M, Baryshnikov I, Karpov B, et al. Differences and similarities of risk factors for suicidal ideation and attempts among patients with depressive or bipolar disorders. J Affect Disord 2016;193:318-30.
[38] Karpov B, Joffe G, Aaltonen K, Suvisaari J, Baryshnikov I, Näätänen P, et al. Anxiety symptoms in a major mood and schizophrenia spectrum disorders. Eur Psychiatry 2016;37:1-7.

[39] World Health Organization. International classification of disease, 10th ed., Geneva: WHO; 1992

[40] Sheehan DV. The anxiety disease. New York, NY, USA: Charles Scribners Sons; 1983.

[41] Sheehan DV, Harnett-Sheehan K, Raj BA. The measurement of disability. Int Clin Psychopharmacol 1996;11(Suppl. 3):89-95.

[42] Beck AT, Ward CH, Mendelson M, Mock J, Erbaugh J. An inventory for measuring depression. Arch Gen Psychiatry 1961;4:561-71.

[43] Schwarzer R, Jerusalem M. Generalized Self-Efficacy Scale. In: Weinman J, Wright S, Johnston M (eds.). Measures in health psychology: a user's portfolio. Causal and control beliefs. Windsor, UK: NFER-NELSON; 1995. p. 35-37.

[44] Zanarini MC, Vujanovic AA, Parachini EA, Boulanger JL, Frankenburg FR, Hennen J. A screening measure for BPD: the McLean Screening Instrument for Borderline Personality Disorder (MSI-BPD). J Pers Disord 2003;17(6):568-73.

[45] IBM SPSS Statistics for Windows, Version 22.0. Released 2013. Armonk, NY: IBM Corp; 2005.

[46] van der Voort TY, Seldenrijk A, van Meijel B, Goossens PJ, Beekman AT, Penninx BW, et al. Functional versus syndromal recovery in patients with major depressive disorder and bipolar disorder. J Clin Psychiatry 2015;76(6): e809-14 [Physicians Postgraduate Press, Inc, United State]

[47] Simonsen C, Sundet K, Vaskinn A, Ueland T, Romm KL, Hellvin T, et al. Psychosocial function in schizophrenia and bipolar disorder: relationship to neurocognition and clinical symptoms. J Int Neuropsychol Soc 2010;16(5): 771-83 [England].

[48] Hendriks SM, Spijker J, Licht CM, Hardeveld F, de Graaf R, Batelaan NM, et al. Long-term work disability and absenteeism in anxiety and depressive disorders. J Affect Disord 2015;178:121-30.

[49] Rosa AR, Franco C, Martinez-Aran A, Sanchez-Moreno J, Reinares M, Salamero $\mathrm{M}$, et al. Functional impairment in patients with remitted bipolar disorder. Psychother Psychosom 2008;77(6):390-2.

[50] Goldberg JF, Harrow M. A 15-year prospective follow-up of bipolar affective disorders: comparisons with unipolar nonpsychotic depression. Bipolar Disord 2011;13(29):155-63.

[51] Disner SG, Beevers CG, Haigh EA, Beck AT. Neural mechanisms of the cognitive model of depression. Nat Rev Neurosci 2011;12(8):467-77.

[52] Sönmez N, Rossberg JI, Evensen J, Barder HE, Haahr U, Ten Velden Hegelstad W, et al. Depressive symptoms in first-episode psychosis: a 10-year follow-up study. Early Interv Psychiatry 2016;10(3):227-33.

[53] Johnson S, Sathyaseelan M, Charles H, Jacob KS. Predictors of disability: a 5year cohort study of first-episode schizophrenia. Asian J Psychiatr 2014;9:4550.

[54] Harvey PD. Disability in schizophrenia: contributing factors and validated assessments. J Clin Psychiatry 2014;75(Suppl. 1):15-20.

[55] Braga RJ, Reynolds GP, Siris SG. Anxiety comorbidity in schizophrenia. Psychiatry Res 2013;210(1):1-7.

[56] Alptekin K, Erkoc S, Gogus AK, Kultur S, Mete L, Ucok A, et al. Disability in schizophrenia: clinical correlates and prediction over 1-year follow-up. Psychiatry Res 2005;135(2):103-11.

[57] Razzano LA, Cook JA, Burke-Miller JK, Mueser KT, Pickett-Schenk SA, Grey DD, et al. Clinical factors associated with employment among people with severe mental illness: findings from the employment intervention demonstration program. J Nerv Ment Dis 2005;193(11):705-13.

[58] Catty J, Lissouba P, White S, Becker T, Drake RE, Fioritti A, et al. Predictors of employment for people with severe mental illness: results of an international six-centre randomised controlled trial. Br J Psychiatry 2008;192(3):224-31.

[59] Depp CA, Mausbach BT, Bowie C, Wolyniec P, Thornquist MH, Luke JR, et al. Determinants of occupational and residential functioning in bipolar disorder. J Affect Disord 2012;136(3):812-8.

[60] Hayhurst KP, Massie JA, Dunn G, Lewis SW, Drake RJ. Validity of subjective versus objective quality of life assessment in people with schizophrenia. BMC Psychiatry 2014;14 [365-014-0365-x].

[61] Bengtsson-Tops A, Hansson L, Sandlund M, Bjarnason O, Korkeila J, Merinder L, et al. Subjective versus interviewer assessment of global quality of life among persons with schizophrenia living in the community: a Nordic multicentre study. Qual Life Res 2005;14(1):221-9.

[62] Harvey PD. Assessing disability in schizophrenia: tools and contributors. J Clin Psychiatry 2014;75(10):e27.

[63] Mantere O, Suominen K, Leppämäki S, Valtonen H, Arvilommi P, Isometsä E. The clinical characteristics of DSM-IV bipolar I and II disorders: baseline findings from the Jorvi Bipolar Study (JoBS). Bipolar Disord 2004;6(5):395405.

[64] Melartin TK, Rytsala HJ, Leskela US, Lestela-Mielonen PS, Sokero TP, Isometsa ET. Current comorbidity of psychiatric disorders among DSM-IV major depressive disorder patients in psychiatric care in the Vantaa Depression Study. J Clin Psychiatry 2002;63(2):126-34. 